\title{
Perencanaan Pemeliharaan Mesin Cement Mill Menggunakan Metode Overall Equipment Effectiveness di Industri Manufaktur Semen
}

\author{
Steven Aeron Seagal ${ }^{1}$, Anita Christine Sembiring ${ }^{2}$, Irwan Budiman ${ }^{3}$ \\ ${ }^{1}$ Teknik Industri, Universitas Prima Indonesia, Medan \\ ${ }^{2}$ Teknik Industri, Universitas Prima Indonesia, Medan \\ ${ }^{3}$ Teknik Industri, Universitas Prima Indonesia, Medan \\ *Email: stevenhutauruk15@gmail.com
}

\begin{abstract}
Abstrak
Pada umumnya proses produksi pastilah memerlukan sebuah mesin untuk melaksanakan tiap proses yang diinginkan. Begitu pula dengan perusahaan yang diteliti di PT Semen Padang yang berlokasi Kota Dumai, Riau. Dari penelitian yang dilakukan, perusahaan memiliki permasalahan pada hasil produksi yang tidak maksimal dan mengakibatkan tidak tercapainya target produksi. Dengan permasalahan tersebut, penelitian bertujuan untuk mengetahui penyebab tidak tercapainya hasil produksi pada mesin cement mill. Dalam tujuan tersebut, tentunya ada metode yang digunakan dalam mencapainya yaitu metode Overall Equipment Effectiveness (OEE). Hasil yang didapat ialah, nilai rata-rata availability rate tahun 2019 dan 2020 ialah 99,64\% dan 99,49\%. Performance rate ialah 59,28\% dan 28,82\%. Quality rate ialah 99,99\% dan $99,99 \%$. OEE ialah $59,08 \%$ dan $28,68 \%$. Kesimpulan yang didapat, produksi tidak mencapai target dikarenakan tidak tercapainya nilai rata-rata performace rate dan OEE yang disebabkan tingginya nilai actual cycle time dan operating time serta rendahnya nilai ideal cycle time dan actual output.
\end{abstract}

Kata kunci: OEE, Mesin Produksi, Pemeliharaan, Proses Produksi

\section{PENDAHULUAN}

Setiap perusahaan pastinya tidak akan pernah jauh dari yang namanya mesin dan produksi, terlebih perusahaan yang bekerja pada bidang produksi tentunya. PT Semen Padang sendiri adalah sebuah perusahaan yang bergerak pada bidang industri produsen semen. Melalui penggunaan metode Overall Equipment Effectiveness (OEE), dapat diperoleh dan diketahui tingkat efektivitas kerja pada suatu mesin yang ingin diteliti, sehingga dapat diketahui hal beserta alasan yang menjadikan tidak maksimal dan tidak tercapainya hasil produksi yang diperoleh. Metode Overall Equipment Effectiveness sendiri, terdiri dari tiga macam rate, yaitu: availability rate, performance rate dan quality rate. Dimana tiap rate ini juga nantinya memiliki tingkat persentase, sebagai penentu hasil produksi telah maksimal atau tidak. Dalam menghasilkan produk, tentunya perusahaan memiliki proses untuk melakukannya. Berikut alur atau proses dalam pembuatan semen di PT Semen Padang yang dapat dilihat pada gambar 1 dibawah ini.

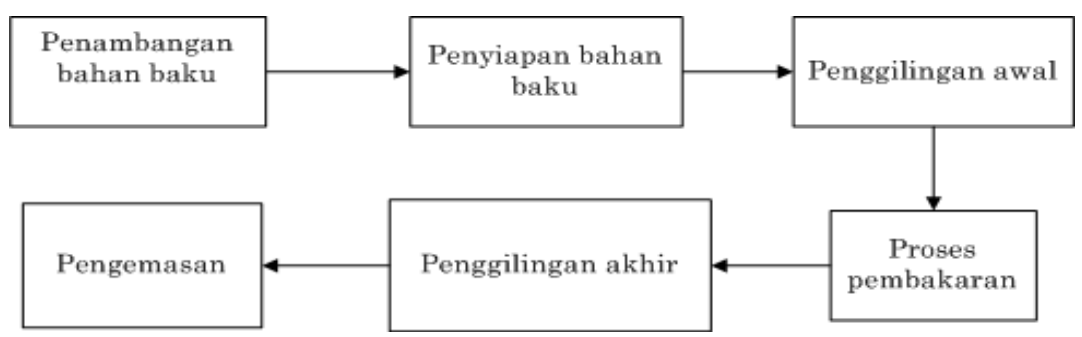

Gambar 1. Flowchart proses produksi produksi PT Semen Padang.

\section{BAHAN DAN METODE Bahan Penelitian}


Objek penelitian ini ialah mesin cement mill di PT Semen Padang. Data yang harus diperoleh untuk melaksanakan penelitian ini ialah jumlah hari kerja, jam kerja (available time), lama mesin beristirahat (planned time), lama mesin mengalami kerusakan (down time), jumlah produk yang diinginkan perusahaan (plan), jumlah produk yang diproses (processed amount), produk cacat (defect product). Dan data yang harus diperoleh yakni tahun 2019 dan 2020. Dikarenakan penulis ingin mengetahui adakah dampak yang diperoleh selama terjadinya pandemi Covid-19 yang terjadi pada tahun 2020. Metode yang digunakan ialah Overall Equipment Effectiveness (OEE). OEE merupakan metode yang digunakan untuk mengevaluasi seberapa capaian performansi sebuah peralatan industi dan sebagai alat ukur guna menjaga peralatan industri tersebut pada kondisi yang ideal. Didalam OEE dapat mengetahui beberapa hal yang menjadi tidak tercapainya hasil produksi yang maksimal. Seperti, gambaran pemanfaatan waktu yang tersedia untuk kegiatan operasi mesin/peralatan.

\section{Langkah-Langkah Penelitian.}

Setelah memperoleh data perusahaan yang diinginkan, maka dapat dilakukan pengerjaan pada tiap rate, seperti availability rate, performance rate, quality rate dan OEE itu sendiri. Berikut penjelasan tiap rate tersebut.

A. Availability rate

Memiliki nilai standar internasional $>90 \%$

Availability $=\frac{\text { Operating Time }}{\text { Loading Time }} \times 100 \%$

Operating Time $=$ Loading Time - Downtime

Loading Time $=$ Available Time - Planned Time

B. Performance rate

Memiliki nilai standar internasional $>95 \%$

Performance rate $=\frac{\text { Actual Output } x \text { Actual Cycle Time }}{\text { Operating Time }}$

Actual output $=\frac{\text { Available Time }}{\text { Planned Time }+ \text { Down Time }}$

Ideal cycle time $=\frac{\text { Loading Time }}{\text { Planned Time }}$

Actual cycle time $=\frac{\text { Operating Time }}{\text { Actual Output }} \times 100 \%$

C. Quality rate

Memiliki nilai standar internasional $>99 \%$

Quality rate $=\frac{\text { Processed Amount }- \text { Defect Product }}{\text { Processed Amount }} \times 100 \%$

D. Overall Equipment Effectiveness (OEE)

Memiliki nilai standar internasional $>85 \%$

$\mathrm{OEE}=$ Availability $\times$ Performance $\times$ Quality

Setelah melakukan perhitungan pada tiap rate, kemudian dilakukan perhitungan nilai rata-rata dari masing-masing rate agar dapat diketahui rate tersebut mencapai ataupun melampaui nilai standar internasional atau tidak.

\section{HASIL DAN PEMBAHASAN}

Pada bagian ini akan diuraikan mengenai hasil penelitian serta pembahasan dari hasil peneilitian tersebut. Hasil penelitian yang disajikan dalam bentuk tabel dan grafik yang 
JURITI PRIMA (Junal Ilmiah Teknik Industri Prima)

Vol. 4 No 2, Juni 2021

e-ISSN: 2581-057X

merupakan hasil dari penilitian. Tabel dan grafik tersebut ditampilkan sesuai dengan jenis sub bahasan sehingga diharapkan dapat memudahkan pembaca dalam memahami hasil penelitian ini. Pembahasan yang tercakup ialah sebagai berikut.

\section{Pengumpulan Data.}

Setelah mengetahui mengenai data yang akan dikumpulkan, berikut perolehan data yang dihasilkan pada tahun 2019 dan 2020 di PT Semen Padang. Dapat dilihat pada tabel 1 dan tabel 2 dibawah ini.

Tabel 1. Data perusahaan tahun 2019

\begin{tabular}{|c|c|c|c|c|c|c|c|c|c|}
\hline Bulan & Tahun & $\begin{array}{l}\text { Hari } \\
\text { Kerja } \\
\text { (Hari) }\end{array}$ & $\begin{array}{l}\text { Waktu } \\
\text { Kerja } \\
\text { (Jam) }\end{array}$ & $\begin{array}{l}\text { Mesin } \\
\text { Istirahat } \\
\text { (Hari) }\end{array}$ & $\begin{array}{l}\text { Mesin } \\
\text { Rusak } \\
\text { (Hari) }\end{array}$ & $\begin{array}{c}\text { Jumlah } \\
\text { Produk Yang } \\
\text { Diinginkan }\end{array}$ & $\begin{array}{c}\text { Jumlah } \\
\text { Produk } \\
\text { Yang } \\
\text { Dihasilkan }\end{array}$ & $\begin{array}{c}\text { Cacat } \\
\text { Produk }\end{array}$ & $\begin{array}{c}\text { Produk } \\
\text { Yang } \\
\text { Diproses }\end{array}$ \\
\hline Januari & 2019 & 26 & 624 & 3 & 2 & 2.000 .000 & 125 & 185 & 1.750 .430 \\
\hline Februari & 2019 & 25 & 600 & 2 & 2 & 2.000 .000 & 150 & 175 & 1.855 .035 \\
\hline Maret & 2019 & 25 & 600 & 4 & 2 & 2.000 .000 & 100 & 182 & 1.757 .760 \\
\hline April & 2019 & 24 & 576 & 3 & 3 & 2.000 .000 & 96 & 190 & 1.675 .588 \\
\hline Mei & 2019 & 27 & 648 & 1 & 3 & 2.000 .000 & 162 & 170 & 1.860 .650 \\
\hline Juni & 2019 & 22 & 528 & 5 & 3 & 2.000 .000 & 66 & 165 & 1.860 .553 \\
\hline Juli & 2019 & 27 & 648 & 11 & 3 & 2.000 .000 & 46 & 198 & 1.556 .044 \\
\hline Agustus & 2019 & 26 & 624 & 2 & 2 & 2.000 .000 & 156 & 173 & 1.856 .970 \\
\hline September & 2019 & 25 & 600 & 3 & 2 & 2.000 .000 & 120 & 180 & 1.765 .455 \\
\hline Oktober & 2019 & 27 & 648 & 3 & 1 & 2.000 .000 & 162 & 165 & 1.800 .764 \\
\hline November & 2019 & 24 & 576 & 2 & 2 & 2.000 .000 & 144 & 125 & 1.988 .525 \\
\hline Desember & 2019 & 28 & 672 & 2 & 1 & 2.000 .000 & 224 & 112 & 2.155 .985 \\
\hline
\end{tabular}

Tabel 2. Data perusahaan tahun 2020 (masa Covid-19)

\begin{tabular}{|c|c|c|c|c|c|c|c|c|c|}
\hline Bulan & Tahun & $\begin{array}{c}\text { Hari } \\
\text { Kerja } \\
\text { (Hari) }\end{array}$ & $\begin{array}{l}\text { Waktu } \\
\text { Kerja } \\
\text { (Jam) }\end{array}$ & $\begin{array}{l}\text { Mesin } \\
\text { Istirahat } \\
\text { (Hari) }\end{array}$ & $\begin{array}{l}\text { Mesin } \\
\text { Rusak } \\
\text { (Hari) }\end{array}$ & $\begin{array}{c}\text { Jumlah } \\
\text { Produk } \\
\text { Yang } \\
\text { Diinginkan }\end{array}$ & $\begin{array}{c}\text { Jumlah } \\
\text { Produk } \\
\text { Yang } \\
\text { Dihasilkan }\end{array}$ & $\begin{array}{l}\text { Cacat } \\
\text { Produk }\end{array}$ & $\begin{array}{c}\text { Produk } \\
\text { Yang } \\
\text { Diproses }\end{array}$ \\
\hline Januari & 2020 & 20 & 480 & 6 & 3 & 2.000 .000 & 53 & 140 & 1.800 .100 \\
\hline Februari & 2020 & 22 & 528 & 4 & 2 & 2.000 .000 & 88 & 265 & 1.900 .025 \\
\hline Maret & 2020 & 24 & 576 & 3 & 1 & 2.000 .000 & 144 & 150 & 1.700 .050 \\
\hline April & 2020 & 26 & 624 & 4 & 2 & 2.000 .000 & 104 & 523 & 1.700 .080 \\
\hline Mei & 2020 & 25 & 600 & 2 & 3 & 2.000 .000 & 120 & 280 & 1.900 .010 \\
\hline Juni & 2020 & 26 & 624 & 4 & 4 & 2.000 .000 & 78 & 260 & 1.804 .068 \\
\hline Juli & 2020 & 25 & 600 & 3 & 4 & 2.000 .000 & 86 & 270 & 1.650 .075 \\
\hline Agustus & 2020 & 26 & 624 & 4 & 5 & 2.000 .000 & 69 & 190 & 1.820 .050 \\
\hline September & 2020 & 27 & 648 & 3 & 3 & 2.000 .000 & 108 & 230 & 1.887 .602 \\
\hline Oktober & 2020 & 24 & 576 & 4 & 3 & 2.000 .000 & 82 & 233 & 1.950 .750 \\
\hline November & 2020 & 25 & 600 & 2 & 4 & 2.000 .000 & 100 & 145 & 2.120 .500 \\
\hline Desember & 2020 & 27 & 648 & 3 & 2 & 2.000 .000 & 130 & 115 & 2.250 .320 \\
\hline
\end{tabular}

\section{Pengolahan Data.}

Setelah mendapatkan seluruh data perusahaan yang diinginkan, maka selanjutnya dapat dilakukan perhitungan data untuk memperoleh setiap nilai dan rata-rata dari availability rate, performance rate, quality rate dan OEE. Dan pada penilitian ini tiap rate memerlukan dua kali pengerjaan dikarenakan data yang dicari ialah dalam rentang dua tahun. Maka dari itu memerlukan pengerjaan pada tahun 2019 dan pada tahun 2020 (masa Covid-19). Pengolahan data tersebut dapat kita lihat dari tabel 3, tabel 4, tabel 5, tabel 6, tabel 7, tabel 8, tabel 9 dan tabel 10 dibawah ini.

Tabel 3. Nilai availability rate

\begin{tabular}{lcc|ccc}
\hline & Tahun 2019 & & \multicolumn{3}{c}{ Tahun 2020 } \\
\hline $\begin{array}{c}\text { Loading } \\
\text { Time }\end{array}$ & $\begin{array}{c}\text { Operating } \\
\text { Time }\end{array}$ & $\begin{array}{c}\text { Availability } \\
(\%)\end{array}$ & $\begin{array}{c}\text { Loading } \\
\text { Time }\end{array}$ & $\begin{array}{c}\text { Operating } \\
\text { Time }\end{array}$ & $\begin{array}{c}\text { Availability } \\
(\%)\end{array}$ \\
\hline 621 & 619 & 99,68 & 474 & 471 & 99,37
\end{tabular}


JURITI PRIMA (Junal Ilmiah Teknik Industri Prima)

Vol. 4 No 2, Juni 2021

e-ISSN: 2581-057X

\begin{tabular}{lll|lll}
\hline 598 & 596 & 99,67 & 524 & 522 & 99,62 \\
596 & 594 & 99,66 & 573 & 572 & 99,83 \\
573 & 570 & 99,48 & 620 & 618 & 99,68 \\
647 & 644 & 99,54 & 598 & 595 & 99,50 \\
523 & 520 & 99,43 & 620 & 616 & 99,35 \\
637 & 634 & 99,53 & 597 & 593 & 99,33 \\
622 & 620 & 99,68 & 620 & 615 & 99,19 \\
597 & 595 & 99,66 & 645 & 642 & 99,53 \\
645 & 644 & 99,84 & 572 & 569 & 99,48 \\
574 & 572 & 99,65 & 598 & 594 & 99,33 \\
670 & 669 & 99,85 & 645 & 643 & 99,69 \\
& TOTAL & $1.195,67$ & & TOTAL & 994,88 \\
& RATA-RATA & 99,64 & & RATA-RATA & 99,49 \\
\hline
\end{tabular}

Tabel 4. Nilai performance rate

\begin{tabular}{cll|lll}
\hline \multicolumn{3}{c|}{ Tahun 2019 } & \multicolumn{3}{c}{ Tahun 2020 } \\
\hline $\begin{array}{c}\text { Actual } \\
\text { Cycle }\end{array}$ & $\begin{array}{c}\text { Ideal Cycle } \\
\text { Time }\end{array}$ & $\begin{array}{c}\text { Performance } \\
\text { Rate } \\
(\%)\end{array}$ & $\begin{array}{c}\text { Actual Cycle } \\
\text { Time }\end{array}$ & $\begin{array}{c}\text { Ideal Cycle } \\
\text { Time }\end{array}$ & $\begin{array}{c}\text { Performance } \\
\text { Rate } \\
(\%)\end{array}$ \\
\hline 496,0 & 207 & 41,73 & 883,13 & 79 & 8,95 \\
397,3 & 299 & 75,25 & 593,18 & 131 & 22,08 \\
594,0 & 149 & 25,08 & 397,22 & 191 & 48,08 \\
593,8 & 191 & 32,17 & 594,23 & 155 & 26,08 \\
397,5 & 647 & 162,75 & 495,83 & 299 & 60,30 \\
787,9 & 104,6 & 13,28 & 789,74 & 155 & 19,63 \\
$1.369,8$ & 57,9 & 4,23 & 691,83 & 199 & 28,76 \\
397,4 & 311 & 78,25 & 887,02 & 155 & 17,47 \\
495,8 & 199 & 40,13 & 594,44 & 215 & 36,17 \\
397,5 & 215 & 54,08 & 691,49 & 143 & 20,68 \\
397,2 & 287 & 72,25 & 594,00 & 299 & 50,34 \\
298,7 & 335 & 112,17 & 496,14 & 215 & 43,33 \\
& TOTAL & 711,39 & & TOTAL & 288,21 \\
& RATA-RATA & 59,28 & & RATA-RATA & 28,82 \\
\hline
\end{tabular}

Tabel 5. Nilai quality rate

\begin{tabular}{cc|c}
\hline & Tahun 2019 & Tahun 2020 \\
\hline $\begin{array}{c}\text { Quality Rate } \\
(\%)\end{array}$ & $\begin{array}{c}\text { Quality Rate } \\
(\%)\end{array}$ \\
\hline & 99,99 & 99,99 \\
99,99 & 99,99 \\
& 99,99 & 99,99 \\
99,99 & 99,97 \\
& 99,99 & 99,99 \\
& 99,99 & 99,99 \\
& 99,99 & 99,98 \\
& 99,99 & 99,99 \\
& 99,99 & 99,99 \\
& 99,99 & 99,99 \\
TOTAL & 99,99 & 99,99 \\
RATA-RATA & 99,99 & 99,99 \\
& $1.199,89$ & 999,86 \\
\hline
\end{tabular}


JURITI PRIMA (Junal Ilmiah Teknik Industri Prima)

Vol. 4 No 2, Juni 2021

e-ISSN: 2581-057X

Tabel 6. Nilai OEE

\begin{tabular}{lll}
\hline & Tahun 2019 & Tahun 2020 \\
\hline & OEE $(\%)$ & OEE $(\%)$ \\
\hline 41,60 & 8,89 \\
74,99 & 22,00 \\
25,00 & 48,00 \\
32,00 & 25,99 \\
161,99 & 59,99 \\
13,20 & 19,50 \\
& 4,21 & 28,57 \\
& 77,99 & 17,33 \\
& 40,00 & 36,00 \\
& 54,00 & 20,57 \\
TOTAL & 72,00 & 50,00 \\
RATA-RATA & 711,99 & 43,20 \\
& 59,08 & 286,82 \\
& & 28,68 \\
\hline
\end{tabular}

\section{Pengaplikasian Data.}

Selesai dalam pengerjaan data dari tiap rate, maka dilakukan pengaplikasian data dalam bentuk grafik. Grafik data dari hasil tiap rate yang telah dikerjakan dapat dilihat pada gambar 2 dan gambar 3 dibawah ini.

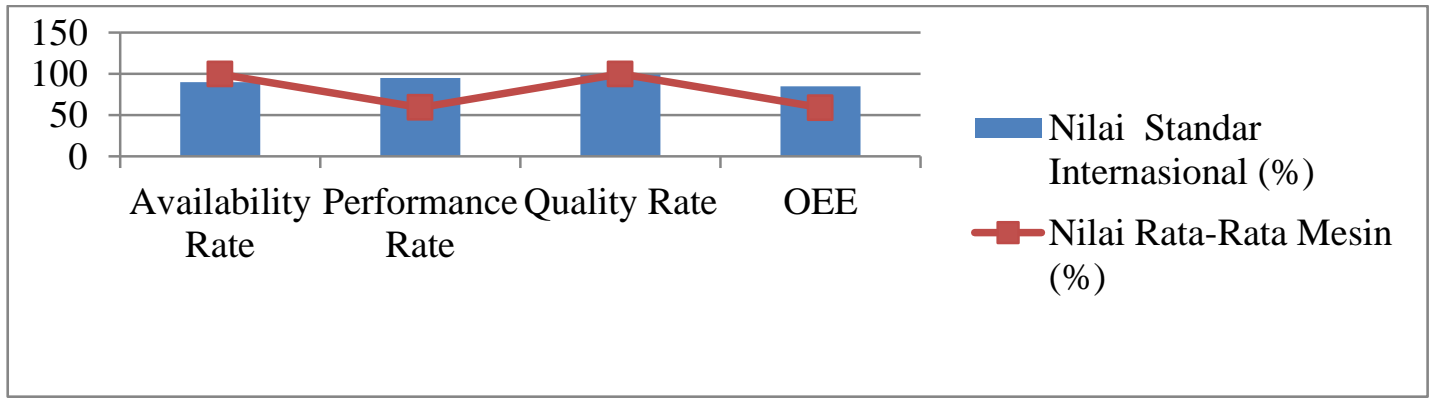

Gambar 2. Grafik perbandingan nilai rata-rata mesin dengan nilai standar internasional tahun 2019

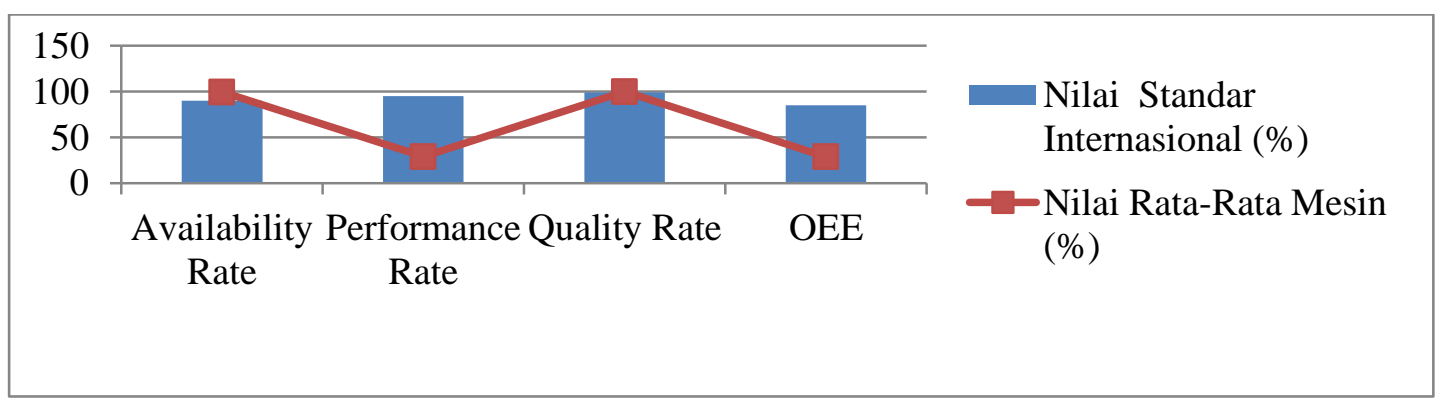

Gambar 3. Grafik perbandingan nilai rata-rata mesin dengan nilai standar internasional tahun 2020 (masa Covid-19)

Pada gambar 2 dan 3 menunjukkan nilai rata-rata mesin dari tiap rate pada tahun 2019 dan 2020. Grafik diatas memperlihatkan rate apa saja yang sudah mencapai nilai standar internasional dan belum mencapai nilai standar internasional. Tentunya, nilai rata-rata mesin pada tiap rate yang belum mencapai standar internasional inilah yang menyebabkan tidak maksimumnya hasil produksi di PT Semen Padang 


\section{KESIMPULAN.}

Dari analisa pengerjaan dalam pengolahan data yang telah dilakukan pada tahun 2019 dan 2020 terhadap mesin cement mill, maka dapat diperoleh kesimpulan sebagai berikut.

1. Pada tahun 2019, ada dua rate yang tidak mencapai nilai standar internasional. Yaitu nilai rata-rata dari performance rate dan nilai rata-rata dari OEE. Dimana nilai rata-rata dari performance rate ialah 59,28\% dan begitu pula untuk nilai rata-rata OEE ialah 59,08\%. Dan untuk rate yang melampaui nilai standar internasional ialah availability rate sebesar 99,64\% dan quality rate sebesar 99,99\%. Pada tahun 2020, memiliki kesamaan dengan tahun 2019 dimana nilai rata-rata performance rate dan OEE sama-sama tidak mencapai nilai standar internasional. Dimana nilai rata-rata performance rate ialah $28,82 \%$ dan nilai rata-rata OEE ialah $28,68 \%$. Begitu pula dengan nilai rata-rata availability rate dan quality rate sama-sama melampaui nilai standar internasional, sama seperti pada tahun 2019. Dimana nilai rata-rata availability rate ialah $99,49 \%$ dan quality rate ialah 99,99\%. Yang menjadi pembeda dari tahun 2019 dan 2020 ialah angka dari nilai rata-rata yang tidak sama terkecuali nilai rata-rata quality rate.

2. Dengan hasil yang didapat, ternyata masa pandemi covid-19 memiliki dampak terhadap hasil produksi pada mesin cement mill di PT Semen Padang. Terbukti tingkat nilai rata-rata tiap rate mengalami penurunan kecuali, pada nilai rata-rata quality rate. Terlebih pada performance rate dan OEE yang turun begitu signifikan walaupun memang sama-sama tidak mencapai nilai standar internasional. Tentu ini dipengaruhi beberapa faktor. Yaitu, jumlah hari kerja yang lebih sedikit dibanding tahun 2019 (sebelum pandemi covid-19) dan lama waktu istirahat serta kerusakan mesin yang lama juga dibanding tahun 2019. Dan untuk kedua tahun yang diteliti ada beberapa analisa yang didapat untuk mencegah tidak tercapainya nilai standar internasional. Yaitu, pada performance rate, nilai actual cycle time dan operating time harus lebih rendah sedangkan nilai ideal cycle time dan actual output harus lebih tinggi. Dan pada OEE, nilai performance rate harus lebih tinggi.

\section{UCAPAN TERIMAKASIH}

Penulis mengucapkan terimakasih untuk Fakultas Teknologi dan Ilmu Komputer Program Studi Teknik Industri Universitas Prima Indonesia yang memberikan kesempatan untuk melakukan penelitian dalam mengaplikasikan mata kuliah manajemen perawatan dan proses produksi dalam penelitian tugas akhir saya. Harapan penulis semoga penelitian ini dapat berguna bagi pembaca lainnya.

\section{DAFTAR PUSTAKA}

[1] Amrani, Mokhtar Ali., Alhomdi, Mansour., Aswaidy, Badiea., Ghaleb, Atef M., AlQubati, Mohyeddine., and Shameeri, Mutahar. (2020). Implementing an integrated maintenance management system for monitoring production lines: a case study for biscuit industry. Journal of Quality in Maintenance Engineering.

[2] Angin, Joel Bastanta Perangin., Manurung, Evin Dunan., dan Siregar, Alfian Hamsi. (2017). Penerapan Total Productive Maintenance dengan menggunakan metode OEE pada turbin uap Type C5 DS II - GVS. Jurnal Energi dan Manufaktur, 10(1), 31.

[3] Bengtsson, Marcus., Andersson, Lars-Gunnar., Ekström, Pontus. (2021). Measuring preconceived beliefs on the results of overall equipment effectiveness - A case study in the automotive manufacturing industry. Journal of Quality in Maintenance Engineering.

[4] Cheah, Chew Keat., Prakash, Joshua., Ong, Kok Seng Ong. (2020). An integrated OEE framework for structured productivity improvement in a semiconductor manufacturing facility. International Journal of Productivity and Performance Management.

[5] Cruz, Arturo., Coffey, Vaughan., Chan, Tommy H.T., Perovic, Miljenka. (2021). Model for the maintenance-focussed heritage building conservation. Journal of Cultural Heritage Management and Sustainable Development. 
[6] Dellagi, Sofiene., Darghouth, Mohamed Noomane. (2021). An improved imperfect maintenance strategy for multiperiod randomly failing equipment with stochastic repair times. Journal of Quality in Maintenance Engineering.

[7] Martins, Rodrigo., Fernandes, Francisco., Infante, Virginia., and Andrade, Antonio R. (2021). Simultaneous scheduling of maintenance crew and maintenance tasks in bus operating companies: a case study. Journal of Quality in Maintenance Engineering.

[8] Mousavi-Nasab, Seyed Hadi., Safari, Jalal., Hafezalkotob, Ashkan. (2019). Resource allocation based on overall equipment effectiveness using cooperative game. Kybernetes, 49(3), 819-834.

[9] Nautiyal, Akhilesh., Sharma, Sunil. (2021). Scientific approach using AHP to prioritize low volume rural roads for pavement maintenance. Journal of Quality in Maintenance Engineering.

[10] Saleem, Faizan., Nisar, Salman., Khan, Muhammad Ali., Khan, Sohaib Zia., Sheikh, Mohammad Aslam. (2017). Overall equipment effectiveness of tyre curing press: a case study. Journal of Quality in Maintenance Engineering, 23(1), 39-56.

[11] Sari, Mahsa Fekri., Darestani, Soroush Avakh. (2019). Fuzzy overall equipment effectiveness and line performance measurement using artificial neural network. Journal of Quality in Maintenance Engineering, 25(2), 340-354.

[12] Sigsgaard, Kristoffer Vandrup., Soleymani, Iman., Mortensen, Niels Henrik., Khalid, Waqas., and Hansen, Kasper Barslund. (2021). Toward a framework for a maintenance architecture. Journal of Quality in Maintenance Engineering.

[13] Teo, Pauline., Gajanayake, Akvan., Jayasuriya, Sajani., Izaddoost, Ali., T Perera reshani., Naderpajouh, Nader., Wong, Peter S.P. (2021). Application of a bottom-up approach to estimate economic impacts of building maintenance projects: cladding rectification program in Australia. Engineering, Construction and Architectural Managemet.

[14] Ylipää, Torbjörn., Skoogh Anders., Bokrantz, Jon., Gopalakrishnan,Maheshwaran. (2017). Identification of maintenance improvement potential using OEE assessment. International Journal of Productivity and Performance Management, 66(1), 126-143.

[15] Zennaro, Ilenia., Battini, Daria., Sgarbossa, Fabio., Persona, Alessandro., Marchi, Rosario De. (2018). International Journal of Quality \& Reliability Management, 35(4), 965-995. 